Human

Development

\title{
Coparenting and child behavior in the context of divorce: A systematic review
}

Tatiane M. B. Ambros, Beatriz P. Coltro, Mauro Luís Vieira, and Fernanda M. Lopes

Psychology Departament, Federal University of Santa Catarina (UFSC)

Submitted: January 21 2021.

Accepted: August 9 ${ }^{\text {th }}, 2021$.

\section{Author Note}

Tatiane M. B. Ambros (D) https://orcid.org/0000-0002-5387-0590

Beatriz P. Coltro (D) https://orcid.org/0000-0002-8471-3141

Mauro Luís Vieira (D) https://orcid.org/00oo-0003-0541-4133

Fernanda M. Lopes (D) https://orcid.org/00oo-0002-4853-7670

Funding: Co-authors Beatriz Pires Coltro and Tatiane M. Baccin Ambrós are Coordination for the Improvement of Higher Education Personnel (CAPES) scholarship holders for Master's and Doctorate degrees at the Federal University of Santa Catarina. Co-author Dr. Mauro Luís Vieira is a CNPq Productivity Scholar (306811/2019-7).

Correspondence concerning this article should be addressed to Tatiane Medianeira Baccin Ambros, Universidade Federal de Santa Catarina, R. Eng. Agrônomo Andrei Cristian Ferreira, s/n, Trindade, Florianópolis, SC, Brazil. CEP 88040-900.E-mail: tatianeambros@yahoo.com.br 


\begin{abstract}
The quality of the coparental relationship after parental divorce significantly affects the parents-children relationship and the child's development. The objective of the study was to conduct a systematic review on the relationship between coparenting and child behavior in divorced families. The systematic review was conducted according to the methodological recommendations of the Preferred Reporting Items for Systematic Reviews and Meta-Analyzes (PRISMA). The searches were carried out in six national and international databases, using the words coparenting, divorce and child behavior, and similar terms, in Portuguese, English and Spanish. Eleven articles published between 2010 and June 2020 were included. The main results of the studies showed that coparental support after divorce favors more positive outcomes in child behavior. However, the existence of coparental conflict represents a risk factor for child behavioral problems, including in families in which coparental support and communication exist.
\end{abstract}

Keywords: coparenting, children, divorce, systematic review, family relationships

\title{
COPARENTALIDADE E COMPORTAMENTO DA CRIANÇA NO CONTEXTO DO DIVÓRCIO: UMA REVISÃO SISTEMÁTICA
}

\begin{abstract}
Resumo
A qualidade da relação coparental após o divórcio dos pais afeta significativamente a relação pais-filhos e o desenvolvimento infantil. O objetivo do estudo foi realizar uma revisão sistemática sobre as relações entre coparentalidade e comportamento da criança em famílias divorciadas. A revisão sistemática foi conduzida de acordo com as recomendações metodológicas do Preferred Reporting Items for Systematic Reviews and Meta-Analyses (PRISMA). As buscas foram realizadas em seis bases de dados, nacionais e internacionais, com os termos coparentalidade, divórcio e comportamento da criança, e termos correlatos, em português, inglês e espanhol. Foram incluídos 11 artigos publicados entre 2010 e junho de 2020. Por meio da análise dos resultados desses artigos, constatou-se que o apoio coparental após o divórcio favorece desfechos positivos no comportamento infantil. Contudo, a existência de conflito coparental representa fator de risco para problemas de comportamento na criança, inclusive em famílias em que há apoio e comunicação coparental.
\end{abstract}

Palavras-chave: coparentalidade, crianças, divórcio, revisão sistemática, relações familiares

\section{COPARENTALIDAD Y COMPORTAMIENTO INFANTIL EN EL CONTEXTO DEL DIVORCIO: UNA REVISIÓN SISTEMÁTICA}

\section{Resumen}

La calidad de la relación coparental después del divorcio de los padres afecta significativamente la relación entre padres e hijos y el desarrollo infantil. El objetivo del estudio fue realizar una revisión sistemática sobre la relación entre coparentalidad y comportamiento del niño en familias divorciadas. La revisión sistemática se realizó conforme las recomendaciones metodológicas del Preferred Reporting 
Items for Systematic Reviews and Meta-Analysis (PRISMA). Las búsquedas se realizaron en seis bases de datos, nacionales e internacionales, con los términos coparentalidad, divorcio y comportamiento infantil en portugués, inglés y español. Se incluyeron 11 artículos publicados entre 2010 y junio de 2020. Los principales resultados de los estudios mostraron que el apoyo coparental después del divorcio favorece resultados más positivos en el comportamiento infantil. Sin embargo, la existencia de conflicto coparental representa factor de riesgo para problemas de comportamiento en niños, incluso en familias que existe el apoyo y la comunicación coparental.

Palabras clave: coparentalidad, niños, divorcio, revisión sistemática, relaciones familiares 
The family is a dynamic and multifaceted social institution made up of those who share a common history and life projects. Considered as one of the main development contexts of its members, particularly during childhood, the family is composed of a series of complex and interdependent emotional relationships among its members that are influenced by macro-social factors, e.g., the culture, history, and socioeconomic aspects (McGoldrick \& Shibusawa, 2016). Thus, several historical changes affect the structure and functions of a family, with marital dissolution and/or divorce as one of the fastest-growing family events in the $21^{\text {st }}$ century in Western society (Greene et al., 2016; Raley \& Sweeney, 2020).

According to data from the Brazilian Institute of Geography and Statistics (Instituto Brasileiro de Geografia e Estatística - IBGE, 2019), divorce applications have increased year after year; in 2018, one divorce was filed for every three civil marriage records in Brazil. Marital dissolution is a family transition event responsible for numerous potentially stressful changes, as it causes imbalances and reorganizations in the roles and functions of family members, especially when the couple has children. In this context, one can argue that the experience of parental divorce during childhood is a risk factor for children's development and its impact will vary according to each child's protective factors and their parents' conditions and abilities to deal with this transition (Greene et al., 2016; Lamela \& Figueiredo, 2016; Sands et al., 2017).

Parents' divorce does not dissolve the family system as a whole, only the parents' marital relationship. Thus, the parental dynamic and communication need to be reorganized to continue to play their childrearing roles. While parenting is defined by a child's relationship with each of its parents, individually, and by the activities and behaviors of parents about their children, coparenting refers to how two or more adults share these tasks in the interplay of roles that relate to children's overall care, involving shared responsibility for their well-being (Feinberg, 2003; McHale et al., 2004). Given this definition, coparenting exists regardless of family structure, as long as two or more people share the responsibility of looking after a child.

Feinberg (2003) proposed a theoretical model to explain the coparenting structure through an ecological and multicomponent view, providing insights into how each component influences parental adjustment, parenting, inter-parental relationship, and child behavior. According to the author, coparenting includes four dimensions, namely: a) childrearing agreement between the parents on parental practices; b) division of labor (household chores, child care, and financial support); c) joint management of family interactions; d) support-undermining concerning the partner's parental role.

Childrearing agreement between the parents is the dimension of coparenting associated with the degree of understanding between the parental dyad in child-related matters, e.g., moral principles, discipline, forms of care, decisions about education, or children's emotional needs. In the division of labor dimension, the coparental dyad shares the obligations of daily childcare routines, as well as the responsibilities for child-related financial, medical, and 
legal matters. This component of coparenting has a significant impact on satisfaction with the coparental relationship and with levels of parental stress, i.e., the greater the division of labor, the lower the stress on parental duties and the greater the satisfaction with the relationship with the other (Feinberg, 2003).

The dimension 'joint management of family interactions' focuses on the interaction between the parental figures and the quality of the structural functioning of the family that depends on this coparenting component. This can be understood as encompassing three aspects: a) management by fathers and mothers of their own behaviors and the communication with others within the family system; b) management of boundaries that are established by parental behaviors and attitudes, which increase the engagement or exclusion of other family members; and c) balanced family relationships, that is, the way in which one member of the parental dyad takes the lead while the other steps back in a given situation. The support-undermining dimension consists of the quality and degree of mutual support between the dyad. Expressions of positive affection, reinforcement, emotional support, and respect for the authority and contributions of the other member of the coparental pair are manifestations of the expected support between parents (Feinberg, 2003).

The same dimensions proposed by Feinberg have correlates and overlaps in the theoretical-methodological proposals presented by Margolin et al. (2001). These authors developed a questionnaire that measured three coparental dimensions: cooperation, conflict, and triangulation. Furthermore, according to the meta-analytic review by Teubert and Pinquart (2010), Feinberg's (2003) model sufficiently contains the component elements by which coparenting is investigated in empirical studies, namely cooperation, agreement, accord in child care and education, conflict, and triangulation. A recent literature review on coparenting assessment instruments argues that its dimensions tend to be located in two distinct groups: those related to support and cooperation (including communication, respect, teamwork, alliance, trust, among others) and others, and those related to coparenting conflict (such as triangulation, misunderstanding, undermining, hostility, restrictive coparenting, among others), with factor analysis indicating one to four-dimensional solutions to the phenomenon (Cusí et al., 2020).

Despite the heterogeneous definitions and conceptualizations of coparenting models, evidence has supported the hypothesis that negative coparenting (also called competitive) poses a risk to the development of psychopathologies in childhood, while cooperative coparenting is considered to be a protective factor for children (Cusí et al., 2020; Teubert \& Pinquart, 2010). In this sense, coparenting is one of the main elements of the family context with marked relevance for child development, regardless of family structure (Solmeyer et al., 2014; Zemp et al., 2018).

When parents divorce, coparenting may represent the only relationship system maintained by the couple (Margolin et al., 2001). There is evidence that, when parents maintain a 
relationship on friendly terms and with sufficient communication after divorce, there are better outcomes for both the child and the parents (Herrero et al., 2020). However, a recent literature review reported inconsistent results for the effects of changes in family structure (such as divorce) on child development. It showed that other factors, such as stress, socioeconomic impacts, and child's characteristics might help explain these effects in the context of the parents' marital dissolution (Hadfield et al., 2018).

The systematic review carried out by Lamela and Figueiredo (2016), which included studies published between 2000 and 2014 on the effects of coparenting in the post-divorce period on child behavior, showed that coparenting conflict is associated with an increase in psychopathological symptoms and behavioral problems in children. On the other hand, comparative studies of married and divorced families showed that children experience the effects of negative or conflictual coparenting regardless of family structure. This finding highlights the fact that divorce is just another context in which coparenting conflicts may arise.

In view of the continuous scientific updates on the topic, reviewing the recent literature can be relevant to identify how coparenting is related to child behavior after parents' separation/divorce, including children's academic performance, well-being, externalizing behaviors (related to impulsiveness, aggressiveness, and hyperactivity) and internalizing behaviors (related to isolation, withdrawal and emotional expression of sadness, depression and/or anxiety) (Bolsoni-Silva et al., 2016). Therefore, this systematic literature review was carried out aiming to analyze the relationships between coparenting and child behavior in divorced families. Considering that coparenting is multidimensional (Feinberg, 2003), this review further analyzes previous findings by looking into specific relationships between the coparenting dimensions and child behavior in divorced families. In addition, it makes a detailed analysis of possible methodological biases found in the retrieved articles.

\section{Method}

This is a systematic review based on the following research question: "What are the relationships between coparenting and child behavior in divorced families?". The components of the research question followed the acronym PECOS: Population, Exposure, Comparator, Outcome and Study. The participants were divorced heterosexual fathers and mothers, with children aged between $\mathrm{o}$ and 12 years old, who responded to some measurement instrument on coparenting (Exposure); with no comparison group ( $C$ is non-applicable); with child behavior as an outcome measure (Outcome); and focusing on papers of quantitative and/or qualitative methods. This review used the description guidelines Preferred Reporting Items for Systematic Reviews and Meta-Analyses (PRISMA) (Moher et al., 2009), but without prior registration of the protocol (the study protocol can be made available by the corresponding author). 


\section{Search criteria and inclusion of material in the review}

A systematic search was carried out in June 2020 to include empirical articles published between 2010 and 2020 (until the month of June), without language of publication restrictions, in the Pubmed, Web of Science, PsycInfo, Scopus, and Scielo databases and in the Virtual Health Library (VHL). This was the complete search strategy, including the Boolean descriptors and operators used: (coparenting) AND (divorce OR divorced OR divorced OR marital dissolution OR separation) AND (child behavior OR child mental health OR child adjustment) and their respective terms in Portuguese and Spanish.

The inclusion criteria were primary (empirical) studies that addressed the relationship between coparenting and child behavior in the context of divorce/separation as a central theme. Exclusion criteria were: a) studies that did not include instruments to measure coparenting or child behavior; b) studies in which the variable child was used as a predictor and not as an outcome or in association with coparenting; c) duplicate or non-scientific articles (not indexed in databases); and d) literature reviews, meta-analyses, editorials, letters, books or book chapters, theses, dissertations, case reports, experience reports, and papers presented in conferences.

\section{Documentary data collection procedures}

After the search step, two independent judges (to minimize selection bias) selected the studies by reading the abstracts, based on the eligibility criteria, using the free-to-use Rayyan ${ }^{\circledR}$ software (Ouzzani et al., 2016). A third judge participated in the discussion in cases of doubt for consensual decision-making. In some cases, the judges had to read the full text to determine whether the study should be included or excluded. Figure 1 shows the flowchart of the steps of searching and selecting the articles. 


\section{Figure 1}

Flowchart of the steps article search and selection

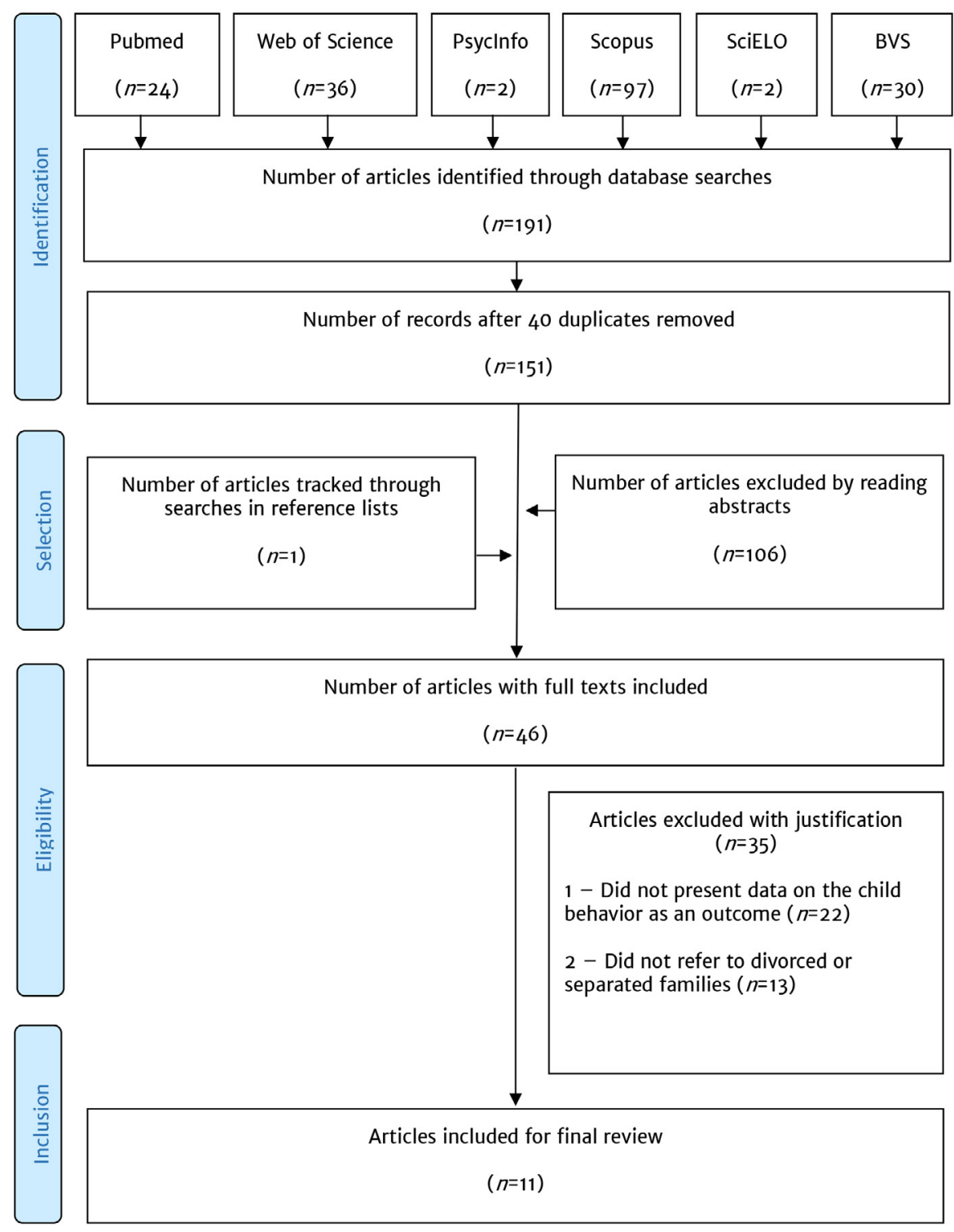




\section{Data extraction and analysis procedures}

Data extraction took place with the help of an Excel spreadsheet, and it was performed independently by the two judges who selected the studies. The third judge reviewed the extracted data by checking the standardized table based on the publication characteristics of the studies included (goals, design, participants, instruments, data collection, and analysis procedures), including outcomes in child behavior and the recommendations and limitations described in the studies.

The methodological quality of the articles was analyzed by applying two checklists of the Joanna Briggs Institute - JBI (2020). The JBI Checklist for Analytical Cross-Sectional Studies (which contains eight items) was used to assess the ten correlational articles, after adapting items 5 and 6 to better identify biases in the studies, while considering their design. Thus, these items were used to assess the presence or absence of intervening variables or control variables (item 5) and whether adequate strategies were described and applied to deal with such variables (item 6). The JBI Checklist for Quasi-Experimental Studies (which contains nine items) was applied to the only quasi-experimental article retrieved, without adaptations.

\section{Results}

\section{Characterization of studies}

This review found studies from only six countries: United States $(n=5)$, Spain $(n=2)$, Portugal $(n=1)$, India $(n=1)$, China $(n=1)$, and Australia $(n=1)$. The samples of the studies consisted of families, including children and/or their respective fathers and mothers who were separated or divorced. In most studies $(n=7)$, mothers were the major participating parent (61\% to $100 \%)$. Amato et al. (2011) did not indicate the respondents' gender. Exceptions were the studies by Dyer et al. (2018), who investigated only fathers' perceptions; and the study by Jiménez-García et al. (2019) collected their data from court documents. In the study by Baxter et al. (2011), teachers also provided information about children and two articles (Baxter et al., 2011; Karberg \& Cabrera, 2020); married parents were also included, in addition to the separated ones. The investigation conducted by Jiménez-Garcia et al. (2019) used files from divorce court proceedings as a data source, accessing the information indirectly.

In most studies, research was based on understanding the effects of divorce on child behavior. Eight articles also included a priori definitions of coparenting, arguing that the phenomenon is a relationship or a joint interaction between parents with the aim of coordinating childrearing activities. There was a consensus that coparenting can be positive or negative depending on the quality of the cooperation, the communication, and the degree of conflict between parents.

The study by Dyer et al. (2018) included the development and validation of a coparenting scale for non-resident fathers with their children. Six articles did not use validated 
measures to assess coparenting by the participants; they referred the use of specific questions about frequency of contact and/or the existence of cooperation or conflict between parents. The main dimensions of coparenting measured by the studies were: coparenting support/cooperation $(n=10)$, coparenting conflict/hostility $(n=7)$, and communication $(n=2)$. Other dimensions include triangulation of the coparental relationship, exposure to conflict, undermining, and maternal gatekeeping. Of the 11 studies, seven measured coparenting through at least two dimensions. Three studies used only positive dimensions of coparenting (support, communication, or cooperation) and one only measured the conflict dimension.

Regarding the investigation of child behavior, three studies used one or more subscales of the Child Behavior Checklist for Ages 6-18 (CBCL/6-18), version for children and adolescents between 6 and 18 years old) to check for child behavior problems (Choi \& Becher, 2019; Herrero et al., 2020; Karberg \& Cabrera, 2020). The Strengths and Difficulties Questionnaire (SDQ, version for children and adolescents between 4 and 16 years old) was used in the study by Lau (2017) along with a self-esteem scale; and also in the study by Lamela et al. (2015), who used only the four subscales for child difficulties. In addition, mothers and teachers answered the SDQ emotional problems subscale in the study by Baxter et al. (2011), together with a series of questions about the emotional state of children, according to their self-report. Other instruments appeared only once in the other studies, such as the Behavior Problem Index (Dyer et al., 2018); a short version of the Social Skills Rating System (SSRS; Beckmeyer et al., 2014); and scales on resilient behaviors (Pandya, 2017). In two studies, a questionnaire was specifically developed to assess child behavior (Amato et al., 2011; Jiménez-García et al., 2019).

Six of the ten correlational studies had high methodological quality; they contained seven or eight items from the checklist (five were assigned "yes" to all items, while one was assigned only one "no"). All studies included items 1 and 2 on the description of the sample inclusion criteria, subjects, and study context. The lowest-scoring item was number 3 on the validity of the instrument for assessment of coparenting. In this item, five studies did not score any points. Of these, two also did not score in item 7 on the validity of the instrument for measuring child behavior (Amato et al., 2011; Jiménez-Garcia et al., 2019); thus, they showed lower methodological quality.

The study by Amato et al. (2011) also did not show all the data resulting from their statistical analyses. In turn, the only study that did not include item 4, on the measure of condition (divorce/separation), was the one by Baxter et al. (2011), which automatically included in the group of separated mothers who did not live with the coparental pair. For the only quasi-experimental study (Pandya, 2017), methodological weaknesses were the absence of a follow-up study, the lack of information about the profile of the participants included in the control group and about whether they were receiving any similar intervention, in addition 
to the intervention of interest (the protocols used to assess the methodological quality can be made available by the corresponding author).

\section{Relationship between coparenting and child behavior}

Three studies identified different profiles (clusters) of post-divorce coparenting among participants according to relationship characteristics between the divorced couple, and they related these profiles to children's behavioral outcomes (Table 1). Amato et al. (2011) found significant differences in child behavior problems among the three profiles, being such differences smaller among families with cooperative coparenting. It is noteworthy that parents in the cooperative coparenting group had significantly higher income and education, while those with lower income and education were in the solo parenting group.

Beckmeyer et al. (2014) also found three coparenting profiles, similar to those reported by Amato et al. (2011). However, the children's behavioral problems and social skills were similar in all groups, without significant differences, which could be explained by the fact that all participants in the sample had previously participated in a post-divorce educational program. Lamela et al. (2015) identified three different coparenting profiles and called them high-conflict coparenting, undermining coparenting, and cooperative coparenting. Fewer externalizing behavior problems were found in the cooperative group compared to the other two groups. Fewer internalizing behavior problems were found among parents who engaged in cooperative coparenting compared to the undermining coparenting group, but not compared to the high-conflict group.

Data from separated couples were compared to those from married and remarried families in the longitudinal study by Baxter et al. (2011). The authors only measured the existence of coparental hostility and identified it as an important explanatory factor for children's emotional well-being. Hostile coparenting was associated with lower emotional well-being in children, regardless of the type of family (married, separated, or remarried), in the perception of mothers and children alike. However, among parents who had a hostile relationship, those who were separated had children with worse emotional well-being scores, as reported by teachers and children, but not by mothers.

The information provided by parents and children was also different in the study by Lau (2017), who investigated relationships between the dimensions of support, conflict, triangulation, and coparental communication. The practice of triangulation in the coparental relationship did not have any significant impact on the children's well-being according to the parents' report; however, according to the responses provided by the children, experiencing triangulation in the coparental conflict represented an important risk factor for their self-esteem. Furthermore, more communication between parents was associated with more emotional symptoms in the child, both in the parents' and children's perception. In regression 
analyses, coparental support was a predictor of less hyperactivity and emotional symptoms in children, while coparental conflict was a predictor of higher scores on these indicators.

Lau (2017) performed a path analysis through which she identified the indirect effect of coparental support on the increase in child hyperactivity resulting from coparental conflict. In addition, she also found an indirect effect of communication and coparental conflict on children's negative emotional symptoms through coparental support. The author also found that there was more coparental support when the child was a girl. To explain these unexpected data, she found that the most supportive parents were the ones living with the child and hypothesized that conflict may stem from a greater burden on one of the parents. As so, this parent not only looks after the child more directly, because they live together, but also provides more support than he or she receives.

Choi and Becher (2019) found that the mother's older age is a protective factor for positive coparenting, while maternal depression is a risk factor. In their explanatory model, positive coparenting was able to predict fewer child behavior problems and less harsh parenting practices. Karberg and Cabrera (2020) developed a model that explained $28 \%$ of the variation in child aggression, emphasizing a significant relationship between marital instability and children's aggressiveness through less coparenting, which was even more pronounced for divorced mothers than for separated mothers (who never got to marry their coparental pairs) who were cohabiting with another partner.

The only study in which positive coparenting was used as a moderator investigated a relationship between family phenomena and child outcomes (anxiety/depressive symptoms and aggressiveness). Herrero et al. (2020) found that coparenting is a protective factor for child behavior as long as parents do not face high levels of conflict. Thus, they demonstrated that coparental support leads to greater negative outcomes for children whose parents are in a high-conflict divorce, as it can increase the child's exposure to an adverse and hostile family system. Furthermore, the authors found that greater family communication was not associated with less coparental conflict, which suggests that other factors maintain conflicts, despite good communication. Such data must be interpreted with caution, as most participants faced a litigious divorce at the time of collection.

In the ex post facto study conducted by Jiménez-Garcia et al. (2019), with 317 lawsuits, a greater proportion of externalizing behavior problems, emotional symptoms, and academic performance problems was found among children of parents who were not coparenting after divorce. The logistic regression analysis performed by the authors showed that the high intensity of conflicts over custody and financial issues between parents caused an eight-fold increase in the negative outcomes in the child, and it was the greatest predictor. Mosmann et al. (2018) investigated children and adolescents with and without clinical psychological symptoms. The authors identified the variables coparental competition, intrusive parental 
practice, child exposure to coparental conflict, and marital conflict as discriminants of children with clinical symptoms. Their findings also showed the coparenting variables with the greatest power of discrimination between the groups, followed by the parenting and conjugality variables. Thus, coparenting acts as an important intervening factor between conjugality and parenting, as it has consequences for the relationship between the parents and their child as well as with their spouses.

In the regression analysis performed by Dyer et al. (2018), with data from 542 low-income parents (men), among the three coparental factors analyzed (alliance, undermining, and maternal gatekeeping), only undermining was positively related to child behavior problems. Finally, the only experimental study retrieved in this review investigated the effect of coparenting arrangements on the effects of an intervention to promote spirituality among children from high-income divorced families. Outcomes that are more positive were found in children who lived with single parents or in cooperative coparenting arrangements than in children whose parents often had conflicting coparenting arrangements or were remarried (Pandya, 2017). Table 1 shows details about the samples and the main results of the studies.

\section{Discussion}

This systematic review aimed to analyze the relationship between coparenting and child behavior in divorced families based on studies conducted in the last ten years. It was assumed that coparenting is a relevant factor for child development outcomes, especially after separation or divorce, as a stressful event that implies changes in the family structure and dynamics, as indicated by McGoldrick and Shibusawa (2016). However, the quality of coparenting is different for each member of the coparenting duo and is also perceived in a specific way by each child (McHale \& Sirotkin, 2019). Thus, it is important to highlight the sampling characteristics of the eleven studies included in the review.

The predominance of mothers in the samples has been identified in other literature reviews on phenomena in the family context (Coltro et al., 2020; Samdan et al., 2020), although social changes point to a progressively greater paternal participation in household chores and childcare activities (Gomes \& Alvarenga, 2016). In addition, it is noteworthy that no study investigated the perception of both members of the coparenting duo about coparenting or about child behavior, which is a methodological limitation, because impressions about family dynamics remain partial. With regard to divorced families, it may be even more important to include both parents in the sample, which contributes to the identification of different perceptions about coparenting and child behavior based on the time spent with children. 


\section{Table 1}

Summary of the results of studies included in the Systematic Review

\begin{tabular}{|c|c|c|}
\hline Author (Year) & Sample & Main results \\
\hline $\begin{array}{l}\text { Amato et } \\
\text { al. (2011) }\end{array}$ & $\begin{array}{l}944 \text { parent/child pairs; children aged between } 7 \text { and } 19 \text { years old. } \\
\text { Parents in the Cooperative Coparenting group had significantly } \\
\text { higher income and education, while those with lower income and } \\
\text { education were in the Solo Parenting group. The Cooperative } \\
\text { Coparenting group was divorced. }\end{array}$ & $\begin{array}{l}\text { Identification of three different coparenting profiles after parental divorce: } \\
\text { Cooperative Coparenting (CC; perception of high levels of coparental } \\
\text { involvement, communication, and cooperation with the non-resident } \\
\text { parent); Parallel Coparenting (PC; non-resident parents are involved in } \\
\text { their children's lives, but hardly communicate with the resident parents } \\
\text { and are perceived by them as having limited participation in the children's } \\
\text { lives); and Solo Parenting (SP; non-resident parents hardly ever saw their } \\
\text { children). There were significantly fewer child behavior problems in } \\
\text { the CC group. }\end{array}$ \\
\hline Baxter et al. (2011) & $\begin{array}{l}4,303 \text { children, of whom } 3640 \text { lived with both biological parents, } \\
663(15 \%) \text { lived with their mothers and stepfathers, and } 560 \\
(13 \%) \text { lived with their mothers alone. Data collected between } \\
2004 \text { and } 2006 \text {. Mothers' responses were collected for } 4,189 \\
\text { children. Teacher responses were collected for } 3,487 \text { children. } \\
4,220 \text { children provided answers in the second stage of collection } \\
\text { (the child was between } 4 \text { and } 5 \text { years old in the first stage and } \\
\text { between } 6 \text { and } 7 \text { years old in the second stage). }\end{array}$ & $\begin{array}{l}\text { Children aged 6-7 years old living with their biological parents have better } \\
\text { emotional well-being than those living with their mothers only, and } \\
\text { coparental hostility was significantly associated (and an important } \\
\text { explanatory factor) with children's emotional well-being. Specifically, } \\
\text { regardless of the family type (married or separated), children whose } \\
\text { parents had a hostile coparental relationship had worse emotional } \\
\text { well-being than those whose parents were not hostile. Among parents } \\
\text { who had a hostile relationship, those who were separated had children } \\
\text { with the worst emotional well-being scores, as reported by teachers and } \\
\text { children, but not by mothers. }\end{array}$ \\
\hline $\begin{array}{l}\text { Beckmeyer et } \\
\text { al. (2014) }\end{array}$ & $\begin{array}{l}270 \text { participants, most of whom were white mothers, with some } \\
\text { degree of higher education. All participants had already } \\
\text { participated in a post-divorce education program. }\end{array}$ & $\begin{array}{l}\text { Three post-divorce coparenting profiles were identified, namely: } \\
\text { Cooperative and Involved Coparenting; Moderately engaged coparenting; } \\
\text { and Infrequent but Conflicting Coparenting. }\end{array}$ \\
\hline $\begin{array}{l}\text { Lamela et } \\
\text { al. (2015) }\end{array}$ & $\begin{array}{l}314 \text { parents, } 71.3 \% \text { women; average of } 5.19 \text { years since the } \\
\text { divorce and high level of education. }\end{array}$ & $\begin{array}{l}\text { Three coparenting profiles were identified: Overt-Conflict Coparenting } \\
\text { (OCC; low agreement, lowest score of all in division of labor, and high } \\
\text { undermining and conflict); Coparent Undermining (CU; high scores on } \\
\text { undermining and low/medium scores on agreement, division of labor, and } \\
\text { conflict); Cooperative Coparenting (CC; high scores on agreement, division } \\
\text { of labor, and low scores on undermining and conflict). The CC group } \\
\text { reported significantly fewer internalizing behavior problems in the children } \\
\text { than in the SC group. The CC group reported significantly lower scores on } \\
\text { externalizing behavioral problems than other groups. }\end{array}$ \\
\hline
\end{tabular}




\begin{tabular}{|c|c|c|}
\hline Author (Year) & Sample & Main results \\
\hline Lau (2017) & $\begin{array}{l}142 \text { separated parents, } 115 \text { women. Only } 8 \text { participants were } \\
\text { remarried. The children's average age was } 10 \text { years old; } 47.2 \% \\
\text { were aged between } 12 \text { and } 17 \text { years old. }\end{array}$ & $\begin{array}{l}\text { Different regression analyses were conducted with data provided by } \\
\text { parents and data provided by children. According to the parents, } \\
\text { coparental support predicted fewer hyperactivity symptoms and emotional } \\
\text { symptoms. Coparental conflict predicted more hyperactivity symptoms } \\
\text { and emotional symptoms. Increased communication between parents was } \\
\text { associated with more emotional symptoms among children. }\end{array}$ \\
\hline Pandya (2017) & $\begin{array}{l}1,893 \text { upper middle class and elite children aged from } 9 \text { to } 12 \\
\text { from } 15 \text { different countries. Measures were taken from the } \\
\text { children's reports. }\end{array}$ & $\begin{array}{l}\text { Children who lived with single parents or in cooperative coparenting } \\
\text { arrangements between their parents scored higher on the resilience and } \\
\text { strength scales than those who often had conflicting coparenting } \\
\text { arrangements or lived with remarried parents. }\end{array}$ \\
\hline Dyer et al. (2018) & $\begin{array}{l}542 \text { parents (only men) who did not live with the focal child and } \\
\text { had low income. }\end{array}$ & $\begin{array}{l}\text { The study for development and validation of a coparenting scale identified } \\
\text { three factors: alliance, undermining and maternal gatekeeping (maternal } \\
\text { mediation). In correlation analyses, undermining, was moderately and } \\
\text { significantly related to child behavior problems. In the predictive validation } \\
\text { analysis (multiple regression), only undermining was positively and } \\
\text { significantly related to child behavior problems. }\end{array}$ \\
\hline $\begin{array}{l}\text { Jiménez-García et } \\
\text { al. (2019) }\end{array}$ & $\begin{array}{l}\text { expost facto study with } 317 \text { separation/divorce lawsuits between } \\
\text { the years } 2009 \text { to } 2016 \text {. }\end{array}$ & $\begin{array}{l}\text { There was a greater proportion of sadness, aggressiveness, disobedience, } \\
\text { low self-esteem, self-injurious behavior, anxiety and irritation, and a } \\
\text { decrease in the academic performance of children whose parents did not } \\
\text { practice coparenting. In logistic regression analyses, the practice of } \\
\text { coparenting was not included. The strongest predictor was high conflict } \\
\text { intensity, indicating that there was an } 8 \text {-fold increase in negative } \\
\text { outcomes for children when parents had high conflict intensity. }\end{array}$ \\
\hline $\begin{array}{l}\text { Choi \& } \\
\text { Becher (2019) }\end{array}$ & $\begin{array}{l}1773 \text { separated mothers. Data collected between } 1998 \text { and } 2000 \\
\text { - longitudinal study. Most participants were relatively young } \\
\text { (mean age of } 26 \text { when the child was approximately } 3 \text { years old) } \\
\text { and black }(64.2 \%) .44 .7 \% \text { had no contact with the child's father. }\end{array}$ & $\begin{array}{l}\text { Supportive coparenting was used to mediate sociodemographic data and } \\
\text { maternal depressive symptoms and harsh parenting and child behavior } \\
\text { problems in a Structural Equation Modeling analysis. Younger mothers } \\
\text { showed less positive coparenting and harsher parenting. More depressive } \\
\text { symptoms in the mothers predicted less positive coparenting, and a higher } \\
\text { level of parental education was able to predict greater positive } \\
\text { coparenting. Positive coparenting was able to predict fewer child behavior } \\
\text { problems and less harsh parenting. }\end{array}$ \\
\hline
\end{tabular}




\begin{tabular}{|c|c|c|}
\hline Author (Year) & Sample & Main results \\
\hline $\begin{array}{l}\text { Karberg \& } \\
\text { Cabrera (2020) }\end{array}$ & $\begin{array}{l}3,387 \text { children who lived with their biological mothers. } \\
\text { Coparenting was measured when children were } 5 \text { years old and } \\
\text { aggressiveness when children were } 9 \text { years old. Data collected } \\
\text { between } 1998 \text { and } 2000 \text {. Representative sample for the } \\
\text { population of large US cities. }\end{array}$ & $\begin{array}{l}\text { A path analysis was conducted; the independent variable was marital } \\
\text { instability and the dependent variable was children's aggressive behavior. } \\
\text { Positive coparenting, paternal involvement, maternal involvement, and } \\
\text { maternal responsiveness were included as mediating variables. Marital } \\
\text { status (married or not) was used as a moderator between the independent } \\
\text { variable and the mediators. The association between marital instability } \\
\text { and children's aggression through coparental support was stronger for } \\
\text { divorced mothers than for mothers separated from former partners who } \\
\text { had a new partner. }\end{array}$ \\
\hline $\begin{array}{l}\text { Herrero et } \\
\text { al. }(2020)\end{array}$ & $\begin{array}{l}309 \text { divorced fathers }(39 \%) \text { and mothers }(61 \%) .71 \% \text { had custody } \\
\text { of their children. The majority } 79 \% \text { were in litigious divorce with } \\
62 \% \text { in administrative/judicial dispute. } 45 \% \text { reported having a } \\
\text { "non-existent" relationship with the other parent. }\end{array}$ & $\begin{array}{l}\text { Positive coparenting was used as a moderator in pathway analysis, } \\
\text { moderating the relationship between family phenomena (family } \\
\text { communication, parents' psychological difficulties, conflict with the } \\
\text { coparenting couple, and socioeconomic consequences for the children) and } \\
\text { children's anxiety/depressive symptoms and aggression. Greater family } \\
\text { communication was related to lower levels of anxiety/depressive } \\
\text { symptoms and aggression. }\end{array}$ \\
\hline
\end{tabular}


Among the 11 studies analyzed here, eight included some measure of conflict, hostility, or undermining between parents, yielding consistent results about the negative effects of a conflicting coparental relationship on child behavior. Teubert and Pinquart (2010) conducted a meta-analysis in which they also found a positive relationship between coparental conflict and children's externalizing behaviors, while triangulation and low coparental cooperation were more associated with internalizing behaviors. This difference was not found in the study by Lamela et al. (2015), who found similar levels of internalizing and externalizing behaviors between coparent undermining and high-conflict coparenting groups. Mosmann et al. (2017), in their study with a Brazilian sample, found a predictive power of coparenting variables on children's internalizing and externalizing symptoms, predominant to the constructs of conjugality and parenthood, thus corroborating findings from research conducted in other countries (Feinberg, 2003; Teubert \& Pinquart, 2010). Similarly, Lau (2017) found a positive relationship between coparental conflict and hyperactivity and emotional symptoms, but not about conduct problems. However, she reported that coparental triangulation negatively and significantly affected children's self-esteem only according to their self-report, not in their mothers' perception (Lau, 2017), converging with the analysis of Teubert and Pinquart (2010).

The findings of this review confirm those of Lamela and Figueiredo (2016) and Raposo et al. (2011), sustaining the post-divorce conflict between parents as the most harmful for children, even though conflict does not concern the coparental dimension. Although Baxter et al. (2011) have reported the conflict measure as referring to coparental conflict, a detailed analysis of the items used to build this indicator showed that the measured conflict did not refer only to decisions about the child. Likewise, the different types and intensity of conflict investigated by Jiménez-García et al. (2019) showed that, in the context of litigious divorce, disputes over financial aspects and child custody were the greatest predictors of negative child outcomes.

Coparental support significantly promoted better levels of psychological adjustment in children, leading to positive consequences in family relationships. Souza (2018) investigated the repercussions of coparenting and paternal involvement in the behavior of children in Brazil, and the results highlighted the importance of positive coparental relationships and paternal involvement (basic care and child play) to understand the behavior of preschool children, especially when considering their adaptive and maladaptive impacts on child development. However, considering the complex interactions between coparenting dimensions, it seems to be relevant to identify how and by whom coparenting support is provided. The analyses reported by Lau (2017), for example, show that the coparental support provided by resident caregivers, compared to that of non-resident caregivers, may indicate the presence of a unilateral burden of childcare, which tends to produce negative outcomes on child behavior. 
Therefore, to better understand the impacts of coparenting support on children, the analysis needs to include factors that characterize parents and children, as well as the context of the families. In situations of higher socioeconomic status and education, for example, parents are expected to be able to offer greater coparental support, as reported by Amato et al. (2011).

Regarding coparental communication, the studies showed effects contrary to expectations (Herrero et al., 2020; Lau, 2017). Thus, simply having more communication between parents is not necessarily positive for children, nor does it help promote their development, especially if higher levels of co-parental conflict accompany this communication. Feinberg (2003) argued that it is the parents' role to control their own behavior; they should be careful about how they communicate with each other, avoid discussing marital issues, and refrain from fighting and/or raising their voice in front of their children. In his understanding, parents should wait for a time when their child is not present to resolve this kind of issue.

Furthermore, the author emphasizes that not all conflicts are harmful to children. In cases in which parents are able to positively manage conflicts, the impacts can be beneficial (or at least not harmful) to children, as they can observe models of how to resolve conflicts in a desirable manner and learn from their parents' example. Segrin (2006) demonstrated that families that use positive communication strategies and seek harmonious interactions among their members tend to be healthier than those that maintain conflicting relationships.

Divorce is not always a negative event; in many cases, it is the best solution when conflicts between the couple have become a routine. The quality of coparenting can positively impact the behavior of children after a separation/divorce. Souza (2000) investigated how children experience their parents' separation and concluded that children have their mental health associated with their parents' well-being and the quality of the relationship established between them. Children are, therefore, at risk when they grow up in a family in which the couple is at constant conflict, regardless of whether their parents live together or apart. The author argues that children of divorced parents can be competent and well-adjusted when their parents can manage marital conflicts during the divorce, and when the mother or father - whoever took custody of the child - is able to provide a positive care environment, despite the stress associated with a single, more overloaded role.

When a couple's separation is inevitable, the conflicts arising from such a choice need to offer opportunities for negotiation and understanding for the sake of the children's development. A child's satisfactory upbringing and healthy development involve a set of physical, cognitive, emotional, affective, and instructive care practices for which both parents are responsible, regardless of whether they are married or separated (Goetz \& Vieira, 2010). Thus, the quality of coparenting and communication, together with coparenting support and low 
frequency of conflict, are some of the most important elements when families go through a process of separation/divorce.

\section{Final Considerations}

Coparenting is an extremely important phenomenon for understanding the relationships between parents and children and the impacts of shared childcare on child development. In the context of divorce, coparenting is one of the subsystems most vulnerable to changes in the family structure, requiring the definition of new agreements and commitments by parents to/with their children and ex-spouses. Most of the studies included in this systematic review had sufficient methodological quality for their data to contribute to the accumulation of empirical evidence regarding the relationship between coparenting and child behavior in divorced families. Their results provide further insights into coparenting as a multidimensional phenomenon, in which different patterns of composition, based on their dimensions, tend to produce different results on child behavior. Therefore, a more complex analysis of coparenting can be made when at least two or more dimensions, as well as their interactions, are considered.

Furthermore, the present results and discussions demonstrate that, although coparental support is beneficial for positive outcomes in child behavior, the characteristics of the family and the family context need to be taken into account for these relationships to be better understood. Likewise, parental conflict continues to be considered as a risk factor to child development, as far as externalizing and/or internalizing behaviors are concerned. However, this result is not unanimous, as it varies according to the context of the divorce. Thus, they suggest that coparenting is determined by a wide range of different factors, as defended by the Ecological Model of Coparenting proposed by Feinberg (2003).

Therefore, this review makes a contribution to other scientific studies on coparenting by providing a rigorous analysis of the methodological aspects and results of the retrieved articles. Some of the relevant contributions are the description of complex interactions of the coparenting dimensions, not only with contextual elements but also with each other, in order to produce effects on child behavior; as well as the indication of divorce as a one-of-a-kind context of transformation of the coparenting relationship, based on the reconfiguration of the family structure.

An analysis of the quality of evidence shows some limitations of the studies: for example, the weakness of the measures used to assess the coparenting dimensions, in addition to the fact that five studies did not indicate their psychometric validity (Amato et al., 2011; Baxter et al., 2011; Choi \& Becher, 2019; Jiménez-García et al., 2019; Karberg et al., 2020). This fact hinders the generalization of the results and reduces the possibility of replicating the research designs used. Furthermore, the predominance of mothers as participants indicates a relevant sampling bias. Thus, it is recommended that future studies should investi- 
gate coparenting from the perspective of both men (parents) and children and collect data from both members of the coparenting pair, which will provide a more reliable picture of family relationships. In addition, researchers should use instruments and measures previously validated for the study population and address a greater number of parenting dimensions. In the context of divorce, above all, it seems important to include the time elapsed since the divorce and other family and contextual factors as control variables in the analysis.

The present systematic review presents methodological limitations, e.g., the exclusion of materials from the gray literature and the non-performance of the step of consultation with experts, which could have reduced possible losses of relevant materials. Nevertheless, the consultation step was performed for the reference list of the included studies, and the PRISMA Guide and standardized protocols were used to assess the methodological quality of the included studies. Another limitation was the fact that the investigation protocol was not registered; yet, it is available upon request to the corresponding author.

In summary, this systematic review provides consistent data that can support the professional practice of psychologists involved with the psychosocial assessment of family systems in the context of divorce and intervention procedures with families and children with a view to promoting child development. For professionals involved with families in divorce proceedings, particularly in the clinical, legal and social care context, this review offers support for providing care to families, aiming at child protection and evidence-based decision-making. Above all, it is scientifically and socially relevant to conduct research that can contribute to the analysis of the complex interplay between individual, family, and contextual factors in the Brazilian scenario. 


\section{References}

Amato, P. R., Kane, J. B., \& James, S. (2011). Reconsidering the "Good Divorce". Family Relations, 60(5), 511-524. https://doi.org/10.1111/j.1741-3729.2011.00666.x

Baxter, J., Weston, R., \& Qu, L. (2011). Family Structure, coparental relationship quality, post-separation paternal involvement, and children's emotional Wellbeing. Journal of Family Studies, 17(2), 86-109. https://doi.org/10.5172/jfs.2011.17.2.86

Beckmeyer, J. J., Coleman, M., \& Ganong, L. H. (2014). Postdivorce Coparenting Typologies and Children's Adjustment. Family Relations, 63(4), 526-537. https://doi.org/10.1111/fare.12086

Bolsoni-Silva, A. T., Loureiro, S. R., \& Marturano, E. M. (2016). Comportamentos internalizantes: Associações com habilidades sociais, recursos do ambiente familiar e depressão materna. Psico, 47(2), 111-120. https://doi.org/10.15448/1980-8623.2016.2.20806

Choi, J. K., \& Becher, E. H. (2019). Supportive Coparenting, Parenting Stress, Harsh Parenting, and Child Behavior Problems in Nonmarital Families. Family Process, 58(2), 404-417. https://doi.org/10.1111/famp.12373

Coltro, B. P., Paraventi, L., \& Vieira, M. L., (2020). Relações entre Parentalidade e Apoio Social: Revisão integrativa de literatura. Contextos Clínicos, 13(1), 1-26. https://doi.org/10.4013/ctc.2020.131.12

Cusí, L. M., Günther-Bel, C., Puigdesens, A. V., Orriols, M. C., \& Costa, J. L. M. (2020). Instruments for the Assessment of Coparenting: A systematic review. Journal of Child and Family Studies, 29(9), 2487-2506. https://doi.org/10.1007/s10826-020-01769-3

Dyer, W. J., Fagan, J., Kaufman, R., Pearson, J., \& Cabrera, N. (2018). Self-perceived Coparenting of Nonresident Fathers: Scale Development and Validation. Family Process, 57(4), 927-946. https://doi.org/10.1111/famp.12331

Feinberg, M. E. (2003). The Internal Structure and Ecological Context of Coparenting: A Framework for Research and Intervention. Parenting: Science and Practice, 3(2), 95-131. https://doi.org/10.1207/S15327922PAR0302_01

Goetz, E., \& Vieira, M. L. (2010). Pai real, pai ideal: O papel paterno no desenvolvimento infantil. Juruá.

Gomes, Q. S., \& Alvarenga, P. (2016). O envolvimento paterno em famílias de diferentes níveis socioeconômicos. Psicologia: Teoria e Pesquisa, 32(3), 1-9. https://doi.org/10.1590/0102-3772e323216

Greene, S. M., Anderson, E. R., Forgatch, M. S., DeGarmo, D. S., \& Hetherington, E. M. (2016). Risco e resiliência após o divórcio. In F. Walsh (Ed.), Processos Normativos da Família: Diversidade e Complexidade (4th ed., pp. 102-127). Artmed.

Hadfield, K., Amos, M., Ungar, M., Gosselin, J., \& Ganong, L. (2018). Do Changes to Family Structure Affect Child and Family Outcomes? A Systematic Review of the Instability Hypothesis. Journal of Family Theory and Review, 10(1), 87-110. https://doi.org/10.1111/jftr.12243

Herrero, M., Martínez-Pampliega, A., \& Alvarez, I. (2020). Family Communication, Adaptation to Divorce and Children's Maladjustment: The Moderating Role of Coparenting. Journal of Family Communication, 20(2), 114-128. https://doi.org/10.1080/15267431.2020.1723592

Instituto Brasileiro de Geografia e Estatística [IBGE]. (2019). Estatísticas do registro civil 2018. https://biblioteca.ibge.gov.br/visualizacao/periodicos/135/rc_2018_v45_informativo.pdf 
Jiménez-García, P., Contreras, L., \& Cano-Lozano, M. C. (2019, January). Types and intensity of postdivorce conflicts, the exercise of coparenting and its consequences on children. Revista Iberoamericana de Psicología Y Salud, 10(1), 48-63. https://doi.org/10.23923/j.rips.2019.01.025

Joanna Briggs Institute. (2020). Critical Appraisal Checklist for Quasi-Experimental Studies. Joanna Briggs Institute.

Karberg, E., \& Cabrera, N., J. (2020). Children's Adjustment Parents' Breakup: The Mediational Effects of Parenting and Coparenting. Journal of Family Issues, 41(10), 1810-1833. https://doi.org/10.1177\%2F0192513X19894347

Lau, Y. K. (2017). Postdivorce Coparenting and Children's Well-Being in Hong Kong. Journal of Divorce \& Remarriage, 58(5), 329-346. https://doi.org/10.1080/10502556.2017.1302237

Lamela, D., Figueiredo, B., Bastos, A., \& Feinberg, M. (2015). Typologies of Post-divorce Coparenting and Parental Well-Being, Parenting Quality and Children's Psychological Adjustment. Child Psychiatry \& Human Development, 47, 716-728. https://doi.org/10.1007/s10578-015-0604-5

Lamela, D., \& Figueiredo, B. (2016). Coparenting after marital dissolution and children's mental health: A systematic review. Jornal de Pediatria, 92(4), 331-342. https://doi.org/10.1016/j.jped.2015.09.011

Margolin, G., Gordis, E. B., \& John, R. S. (2001). Coparenting: A link between marital conflict and parenting in two-parent families. Journal of Family Psychology, 15(1), 3-21. https://doi.org/10.1037/0893-3200.15.1.3

McGoldrick, M., \& Shibusawa, T. (2016). O ciclo vital familiar. In F. Walsh (Ed.), Processos Normativos da Família: Diversidade e Complexidade (4th ed., pp. 375-398). Artmed.

McHale, J. P., Kuersten-Hogan, R., \& Rao, N. (2004). Growing points for coparenting theory and research. Journal of Adult Development, 11(3), 221-234. https://doi.org/10.1023/B:JADE. oooo035629.29960.ed

McHale, J. P., \& Sirotkin, J. T. (2019). Coparenting in diverse family systems. In M. H. Bornstein (Ed.), Handbook of parenting: Being and becoming a parent (Vol. 3, pp. 137-166). New York: Routledge.

Moher, D., Liberati, A., Tetzlaff, J., Altman, D. G., \& Prisma Group. (2009). Preferred reporting items for systematic reviews and meta-analyses: The PRISMA statement. PloS Medicine, 6(7), e1000097. https://doi.org/10.1371/journal.pmed.1000097

Mosmann, C. P., Costa, C. B., Einsfeld, P., Silva, A. G. M., \& Koch, C. (2017). Conjugalidade, parentalidade e coparentalidade: Associações com sintomas externalizantes e internalizantes em crianças e adolescentes. Estudos de psicologia, 34(4), 487-498. https://doi.org/10.1590/1982-02752017000400005

Mosmann, C., Costa, C. B., Silva, A. G. M., \& Luz, S. K. (2018). Filhos com sintomas psicológicos clínicos: Papel discriminante da conjugalidade, coparentalidade e parentalidade. Trends in Psychology, 26(1), 429-442. https://doi.org/10.9788/tp2018.1-17pt

Ouzzani, M., Hammady, H., Fedorowicz, Z., \& Elmagarmid, A. (2016). Rayyan - a web and mobile app for systematic reviews. Systematic Reviews, 5(210). https://doi.org/10.1186/s13643-016-0384-4

Pandya, S. P. (2017). Spirituality for Building Resilience in Children of Divorced Parents: A Cross-Country Experimental Study. Journal of Divorce \& Remarriage, 58(6), 447-468. https://doi.org/10.1080/10502556.2017.1343554 
Raley, R. K., \& Sweeney, M. M. (2020). Divorce, Repartnering, and Stepfamilies: A Decade in Review. Journal of Marriage and Family, 82(1), 81-99. https://doi.org/10.1111/jomf.12651

Raposo, H. S., Figueiredo, B. F., Lamela, D. J., Nunes-Costa, R. A., Castro, M. C., \& Prego, J. (2011). Ajustamento da criança à separação ou divórcio dos pais. Revista de psiquiatria clínica, 38(1), 29-33. https://doi.org/10.1590/S0101-60832011000100007

Samdan, G., Kiel, N., Petermann, N., Rothenfuber, S., Zierul, C., \& Reinelt, T. (2020). The relationship between parental behavior and infant regulation: A systematic review. Developmental Review, 57, 100923. https://doi.org/10.1016/j.dr.2020.100923

Sands, A., Thompson, E. J., \& Gaysina, D. (2017). Long-term influences of parental divorce on offspring affective disorders: A systematic review and meta-analysis. Journal of Affective Disorders, 218, 105-114. https://doi.org/10.1016/j.jad.2017.04.015

Segrin, C. (2006). Invited article: Family interactions and well-being: Integrative perspectives. Journal of Family Communication, 6(1), 3-21. https://doi.org/10.1207/s15327698jfc0601_2

Solmeyer, A. R., Feinberg, M. E., Coffman, D. L., \& Jones, D. E. (2014). The Effects of the Family Foundations Prevention Program on Coparenting and Child Adjustment: A Mediation Analysis. Prevention Science, 15(2), 213-223. https://doi.org/10.1007/s11121-013-0366-x

Souza, R. M. (2000). Depois que papai e mamãe se separaram: Um relato dos filhos. Psicologia: Teoria e Pesquisa, 16(3), 203-211. https://doi.org/10.1590/S0102-37722000000300003

Souza, C. D. (2018). Repercussões da Coparentalidade e do Envolvimento paterno no comportamento da criança pré-escolar em famílias biparentais. [Unpublished Doctoral thesis]. Universidade Federal de Santa Catarina.

Teubert, D., \& Pinquart, M. (2010). The Association Between Coparenting and Child Adjustment: A meta-analysis. Parenting, 10(4), 286-307. https://doi.org/10.1080/15295192.2010.492040

Zemp, M., Johnson, M. D., \& Bodenmann, G. (2018). Within-family processes: Interparental and coparenting conflict and child adjustment. Journal of Family Psychology, 32(3), 299-309. https://doi.org/10.1037/famooo0368

Editorial board
Editor-in-chief
Cristiane Silvestre de Paula
Associated editors
Alessandra Gotuzo Seabra
Ana Alexandra Caldas Osório
Luiz Renato Rodrigues Carreiro
Maria Cristina Triguero
$\quad$ Veloz Teixeira
Section editors
"Psychological Evaluation"
Alexandre Luiz de Oliveira Serpa
André Luiz de Carvalho Braule Pinto
Luiz Renato Rodrigues Carreiro
Vera Lúcia Esteves Mateus
"Psychology and Education"
Alessandra Gotuzo Seabra
Carlo Schmidt
Regina Basso Zanon

\author{
"Social Psychology and \\ Population's Health" \\ Enzo Banti Bissoli \\ Marina Xavier Carpena
}

"Clinical Psychology" Carolina Andrea Ziebold Jorquera Julia Garcia Durand Natalia Becker

\section{"Human Development" \\ Maria Cristina Triguero Veloz Teixeira Rosane Lowenthal}

Technical support

Maria Fernanda Liuti Bento da Silva Camila Fragoso Ribeiro

\author{
Editorial production \\ Publishing coordination \\ Ana Claudia de Mauro
}

\section{Editorial interns}

Élcio Carvalho

Júlia Lins Reis

Pietro Menezes

\section{Language editor \\ Daniel Leão}

\section{Layout designer \\ Acqua}

